\title{
Optical engineering capstone design projects with industry sponsors
}

Robert Bunch, Paul Leisher, Sergio Granieri

Robert M. Bunch, Paul O. Leisher, Sergio C. Granieri, "Optical engineering capstone design projects with industry sponsors," Proc. SPIE 9188, Optics Education and Outreach III, 918804 (15 September 2014); doi: 10.1117/12.2061102

SPIE Event: SPIE Optical Engineering + Applications, 2014, San Diego, California, United States 


\title{
Optical engineering capstone design projects with industry sponsors
}

\author{
Robert M. Bunch*, Paul O. Leisher, and Sergio C. Granieri \\ Department of Physics and Optical Engineering, Rose-Hulman Institute of Technology, 5500 \\ Wabash Avenue, Terre Haute, IN, USA 47803-0345
}

\begin{abstract}
Capstone senior design is the culmination of a student's undergraduate engineering education that prepares them for engineering practice. In fact, any engineering degree program that pursues accreditation by the Engineering Accreditation Commission of ABET must contain "a major design experience based on the knowledge and skills acquired in earlier course work and incorporating appropriate engineering standards and multiple realistic constraints." At Rose-Hulman, we offer an interdisciplinary Optical Engineering / Engineering Physics senior design curriculum that meets this requirement. Part of this curriculum is a two-course sequence where students work in teams on a design project leading to a functional prototype. The students begin work on their capstone project during the first week of their senior year. The courses are deliverable-driven and the students are held accountable for regular technical progress through weekly updates with their faculty advisor and mid-term design reviews. We have found that client-sponsored projects offer students an enriched engineering design experience as it ensures consideration of constraints and standards requirements similar to those that they will encounter as working engineers. Further, client-sponsored projects provide teams with an opportunity for regular customer interactions which help shape the product design. The process that we follow in both soliciting and helping to scope appropriate industry-related design projects will be described. In addition, an outline of the capstone course structure as well as methods used to hold teams accountable for technical milestones will be discussed. Illustrative examples of past projects will be provided.
\end{abstract}

Keywords: education, design, engineering

\section{INTRODUCTION}

Rose-Hulman Institute of Technology is a private university specializing in teaching engineering, mathematics, and science. Our mission is to provide our students with the world's best undergraduate education in engineering, mathematics and science in an environment of individual attention and support. We offer both a B.S. (Optical Engineering) degree and an M.S. (Optical Engineering) degree. The optical engineering degree programs at RoseHulman formally began in 2003 although we had offered degrees in applied optics at both the bachelors and masters level since 1985.[1] With the name change to optical engineering we sought accreditation by ABET and developed the curriculum from the ground up based on the general ABET criteria[2]. In addition to the general criteria, the Engineering Accreditation Commission (EAC) of ABET recently adopted additional specific program criteria that must be met by all Optical, Photonic, and Similarly Named Engineering Programs.[2,3]

One key element of any accredited undergraduate engineering degree programs is a capstone design course.[4] The criteria states that, "Students must be prepared for engineering practice through a curriculum culminating in a major design experience based on the knowledge and skills acquired in earlier course work and incorporating appropriate engineering standards and multiple realistic constraints." [2] The newly adopted specific criteria goes even further to require, "Faculty members who teach courses with significant design content must be qualified by virtue of design experience as well as subject matter knowledge." [2] The optical engineering degree program at Rose-Hulman has a long history of using a project-oriented approach to teach capstone design, similar to many other institutions. [5-7] In this paper we discuss the state of our current capstone design course sequence in optical engineering and engineering physics at Rose-Hulman, describe the process used to solicit client-sponsored projects, and provide examples of recent student team design projects.

*bunch@rose-hulman.edu; phone 812 877-8306; fax 812 877-8023; www.rose-hulman.edu

Optics Education and Outreach III, edited by G. Groot Gregory, Proc. of SPIE Vol. 9188,

918804 (C) 2014 SPIE · CCC code: 0277-786X/14/\$18 · doi: 10.1117/12.2061102 


\section{OPTICAL ENGINEERING/ENGINEERING PHYSICS DESIGN COURSE SEQUENCE}

The Department of Physics and Optical Engineering at Rose-Hulman offers a three-quarter cross-listed engineering design course sequence for both optical engineering and engineering physics majors. The first design course taken in the sequence is a one-quarter long ( 10 weeks) introductory class. This course is followed by a two-quarter long ( 20 weeks) capstone sequence of two courses. Further details of the courses are provided below.

\subsection{Introductory design course: OE/EP415 - Engineering Design I}

The engineering design course sequence begins in the spring quarter of a students' junior year (OE/EP415) and focuses on teaching students the process of engineering design, teamwork, and engineering ethics. The course features several smaller design projects which serve to reinforce the design concepts discussed in lecture, including project planning, prototyping, customer needs/metrics, concept generation/screening/scoring, intellectual property, product prototyping, and product economics/cost.[8]

Currently we have four smaller design project activities that focus on a topic area (mechanical, electrical, thermal, and optical) utilizing the student's knowledge from a previous course but in the form of a problem-based design. Having several mini-project activities also allows us to purposely mix the student teams so that each student works on a team with every other student. At the end of the course, self and peer evaluations are given where we use a Likert-type scale[9] to assess each student's willingness to work on a team with another student again. This data is then factored into capstone team assignments as described in the next section.

\subsection{Capstone design courses: OE/EP416 \& OE/EP417 - Engineering Design II and III}

The two remaining courses in our engineering design sequence (OE/EP416 and 417) begin in the fall quarter of students' senior year. These two project-driven team-oriented courses form the base of our student's capstone engineering design experience. The additional time allotted for the capstone project, two quarters, allows more comprehensive projects in which the students can more fully develop their conceptualization, design, and teamwork abilities. In these courses, the student teams run the design project. Faculty serve as mentors to the teams but the outcomes and deliverables are up to the students.

In a typical year, we have 3 to 5 project teams with 3 to 4 students per team. Most projects are sponsored by an industry partner who serves as the client for the design team. Criteria that we use to solicit and identify suitable design projects is described in more detail in Section 3.

In order to maximize the students' chance for success, it is critical to place them on projects which are of interest. Project preference forms containing a short description of each project goal are given to the students and completed during the first week of OE/EP416. On these forms each student ranks the top three projects that they would like to work on as a capstone design. Information about their interests, familiarity with the client company, and career goals are also solicited (some students have done summer internships with client-companies and want to continue work on a project and some students show interest in employment with a client company). In addition to the student's preference feedback other factors which are taken into account include technical ability, leadership ability, teamwork, and communication skills. Since every student had previously taken OE/EP415, faculty have data on each student's willingness to work with every other student and can be effectively used to avoid conflicts within teams. The final teaming arrangement is made by the faculty advisors. However, we find that students almost always get their first or second project choice.

As the project teams are being organized, they often need to learn about additional topics relevant to the engineering design process including product architecture, industrial design, design for manufacturing and assembly, and robust design. These topics are covered in parallel with project work during the first several weeks of OE/EP416 and are taught using a problem-based approach. Typically, a short lecture is given in class; a problem is posed in some area followed by an activity. For example, reverse engineering a disposable camera teaches the students about design for manufacture and product architecture. We also developed an in-class activity which allows student teams to design a widget and take it to volume production all within a single three-hour laboratory period.[10]

The structure of OE/EP416 and 417 includes time for formal weekly team meetings where minutes are taken and reported to the faculty. Team work experience includes the rotation of team roles among the members of the team. This is carried out during the first half of OE/EP416 to ensure each student exercise the critical leader role. After midterm of the second course a permanent team leader is elected by the team and remains fixed until the end of the project. 
All capstone projects are milestone/deliverable-driven. In order to monitor adequate progress, teams meet with their faculty mentor for a weekly project review. In this meeting the team summarizes work done during the past week, discusses any design problems encountered, reviews goals for the next week, and describes potential risks in meeting project milestones. We have found that a quad chart, as shown in Fig. 1 to be a useful tool in monitoring team progress.

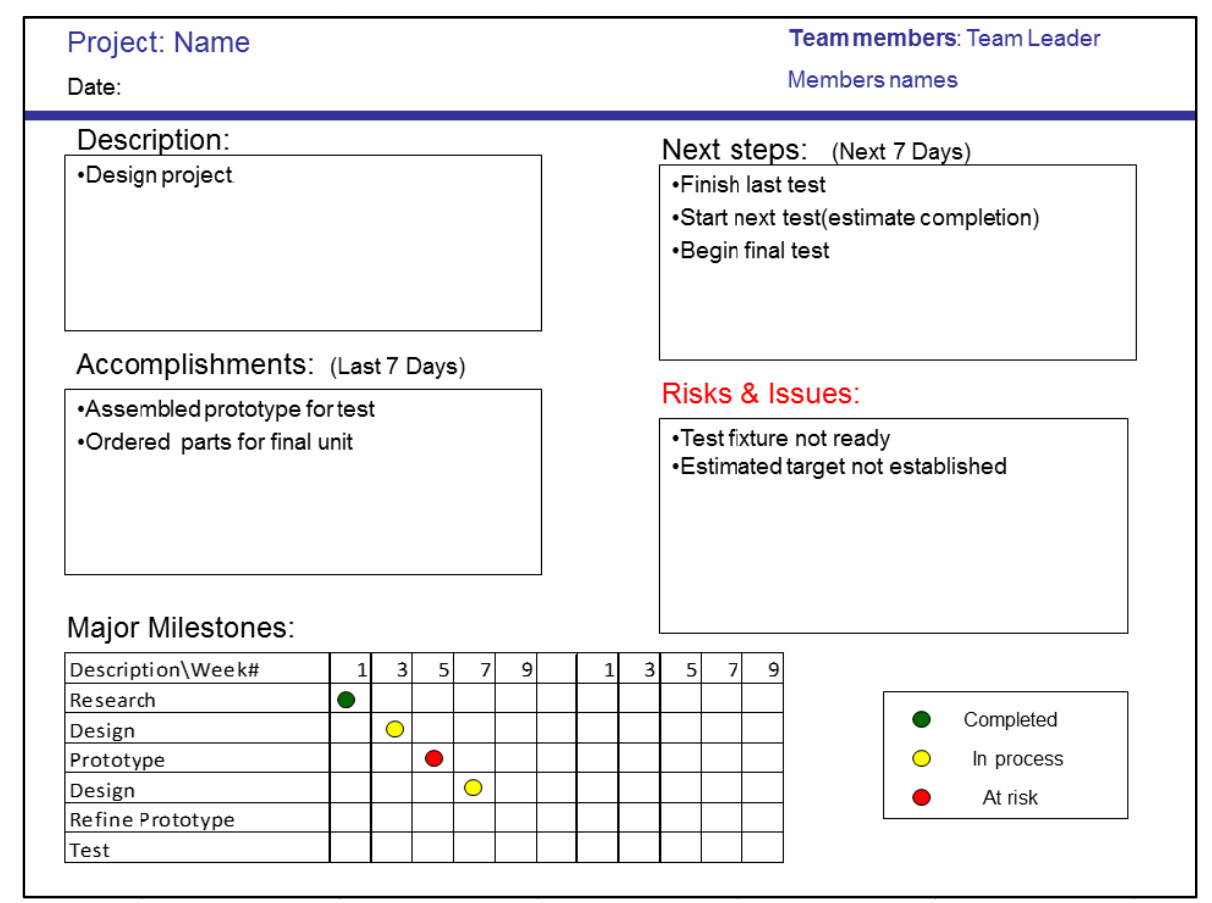

Figure 1. Template of the chart used to monitor the weekly progress of a student design team

As with any design project, technical issues and unforeseen circumstances occur that require changes in the project plan and affect a team's ability to meet milestones. We allow for this to occur and use a change order form process. Any changes must be requested by the team in writing with documented evidence (experimental test data and/or theoretical calculations) provided as to why the change is necessary. Final approval of any changes are at the discretion of all faculty mentors.

OE/EP 416 and 417 each contain midterm and end-of-quarter formal design reviews that include a presentation made by the entire student team. These reviews cover the team's approach to the design problem, high-level design document, product description specification document, project plan, and acceptance test document. Each team provides a Gantt chart for the project that is continuously updated with clear timelines and milestones necessary to complete the project in two quarters.

The culmination of the project experience is a final design review and presentation along with the delivery of the team's prototype, usually scheduled near the end of their final term. The technical quality of the presentation is important and students are also evaluated on oral communication skills. The prototype is evaluated on aesthetics, design requirements, size, compactness, opto-mechanics, sophistication of any electronics, quality of tests, and ability of the overall design to meet or exceed the design specifications. In both courses teams must deliver a written report containing a review of the design process followed and a description of the technical aspects of the design. The comprehensive final report deliverable at the end of the third course also includes the project plan, high level design document, product design specification, and economic analysis. We survey each client sponsor at the end of the project to quantify their overall satisfaction and use this input in the final assessment of project performance. 


\section{WHAT MAKES A SUITABLE CAPSTONE DESIGN PROJECT?}

\subsection{Client-sponsored projects}

We believe that client-sponsored projects offer students an enriched engineering design experience as it ensures appropriate realistic multiple constraints. This approach also provides the students the opportunity to experience firsthand the challenges of customer interaction during the design process. To this end, each year the faculty advisors solicit project ideas from clients.

\subsection{What makes for a "good" project?}

Project topics should be appropriate to Senior-level optical engineering and/or engineering physics students. Four factors which we believe are essential to a "good" project are:

- The project should be challenging, but doable. Projects which require the students to employ their knowledge of their specific discipline and also related engineering disciplines (mechanical, electrical, thermal, and chemical, etc.) are preferred.

- The project should be sufficiently "open" to allow for multiple alternative solutions. Part of the design process which is emphasized in the course is the evaluation of alternative concepts and the process of down-selection.

- The project should have a final hardware deliverable. This is something that will be shipped at the end of the project and that the students are held accountable for.

- The project should be of genuine interest and significance to the client. This is to encourage good engagement between the client and student project team.

\subsection{How are projects/clients chosen and what is the timeline?}

We begin discussion of project topics with potential clients in the spring (March-April). Typically, two-to-three faculty are assigned to team-teach the design course sequence. Each faculty member reaches out to their network of colleagues (many times they are alumni) and request ideas for potential student design projects. Potential clients submit a one-page problem statement for each project to the faculty advisors. Potential projects are evaluated per the criteria in the previous section. While it is possible to have multiple projects from the same client, we try to spread things out to provide projects for as many different clients as possible. External (company-sponsored) projects are given preference over internal (Rose-Human) projects to provide better exposure for the students in the course. The faculty advisors meet to finalize project selections in June and notify clients immediately. Students begin work on the projects in the second week of the Fall quarter, and all projects are completed by mid-February which is the end of our Winter quarter.

\subsection{What are the typical costs to the client?}

Rose-Hulman does not currently require that client companies pay any upfront cost. Student teams are given access to a departmental laboratory space and have the use of any specialized equipment/facilities. Any test equipment and prototyping facilities are arranged as dictated by the specific project. The department allocates a material budget to each team that does not exceed $\$ 100$ (typically), however, we do ask that the client provide any out-of-pocket expenses and specialized items that the students need for the project. Those items can be returned at the end of the project, if necessary. We also ask that in the event that the project exceeds the clients expectations, that they would consider providing a small donation the Physics and Optical Engineering department.

\subsection{What is the level of engagement with the client?}

We expect clients to be attentive customers with a vested interested in the outcome of the student's project - in other words, to be a "good" customer. This really only works if the project is of significant and genuine interest to the company. We ask for a commitment of a company contact person who is willing to communicate (usually by teleconference or email) regularly with the team to answer questions and offer suggestions. Often, the project client sponsors will come on-site for a preliminary meeting and/or for the final presentation and demonstration.

\subsection{What are the benefits to the client?}

The benefit to companies is that it is a great way to get some feasibility project investigated, have your company name known by students, and get an advanced look at some potential employees. 


\section{EXAMPLES OF PRIOR PROJECTS}

\subsection{Example 1 - Project sponsored by Valeo-Sylvania, Fall 2012.}

As an automotive safety device, one of the regulatory requirements for lighting is for the light to meet area requirements. This is called the effective projected luminous lens area (EPLLA) for the light emitting surface. The EPLLA is basically the part of the lamp which can be seen as being lit. The goal of this project was to design and construct a system that is easy to use and produces repeatable measurements of the EPLLA of an automobile brake light. Design constraints included the requirement that the device record the image of the lamp and compute the EPLLA, the setup needed to provide a simple user interface with a cycle time less than one hour per test. The system also needed to be adaptable for use in the client's existing goniophotometer so that measurements could be taken at multiple angles.
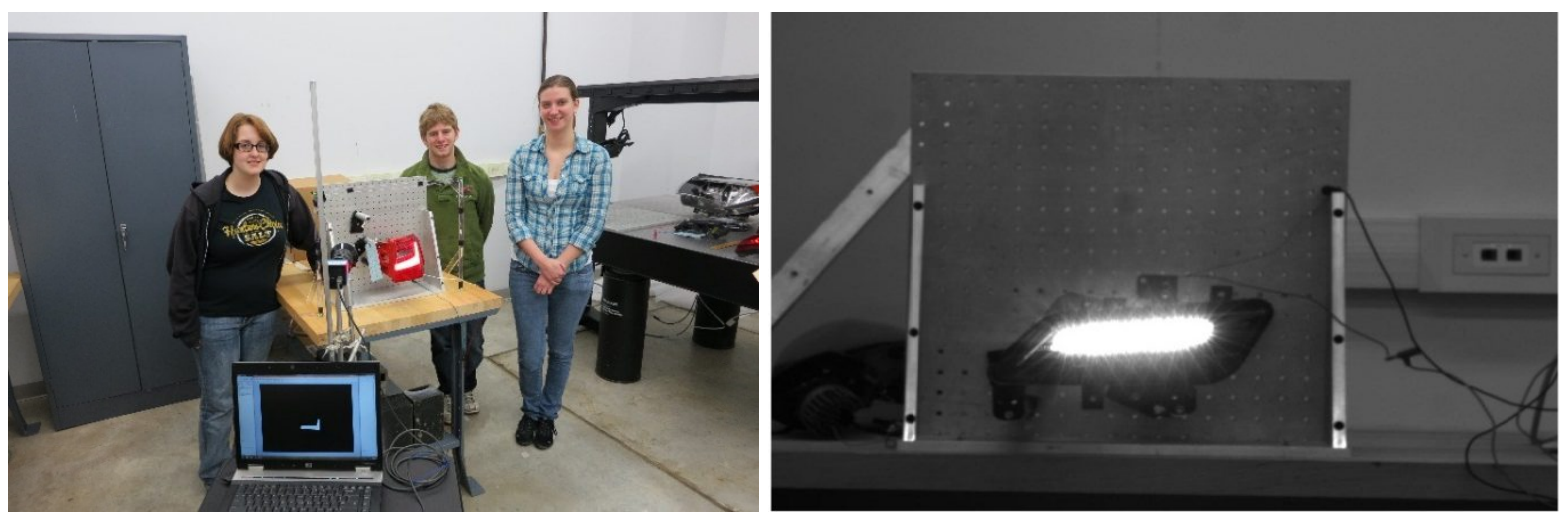

Figure 2. (a) Valeo-Sylvania team with their prototype and (b) Image captured by the system and ready for analysis.

\subsection{Example 2 - Project sponsored by nLight, Fall 2012.}

Advancements in the performance of single-emitter diode lasers combined with precision optical alignment manufacturing processes has led to a rapid proliferation in high-brightness diode laser modules. At the core of this advancement is the brightness of the diode laser pump source. One of the critical laser performance parameters which must be measured by high power diode laser vendors is the optical near-field emission profile. The goal of this design project was to develop a system to profile the near-field intensity of a high power laser emitter. The desired technical specifications are as follows: the system must be able to profile the near-field of a $100 \mu \mathrm{m}$ stripe laser diode operating at any wavelength from 800 to $1000 \mathrm{~nm}$; the system must accept light up to a $45^{\circ}$ half-angle and operate diffractionlimited; the system magnification must be accurately known and faithfully reproduced from measurement to measurement.
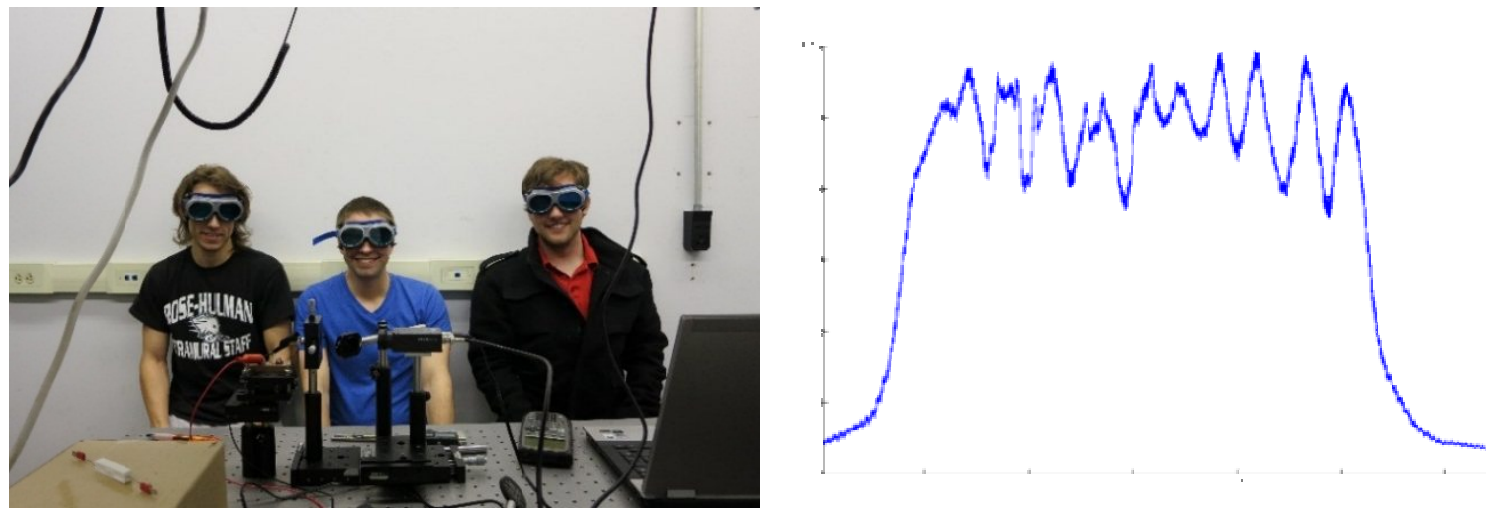

Figure 3. (a) nLight team with their prototype test setup and (b) Overlay of 100 near-field profile measurements taken over a 15 -minute period. 


\subsection{Example 3 - Project sponsored by DILAS, Fall 2012.}

Volume Bragg gratings (VBGs) are holographically recorded diffraction gratings which can be used to narrow the emission spectral bandwidth of laser diodes. One of the challenges associated with this technology is the alignment process, which can take considerable time due to the high degree of precision required. The goal of this design project was to design and demonstrate a precision alignment station/tool for aligning volume Bragg gratings (VBGs) to high power laser bars for wavelength locking. The system needed to work for lensed $\mathrm{cm}$-wide diode laser bars with output powers of $>100 \mathrm{~W}$ with a goal of performing fully automated (hands-free) alignment of the VBG.
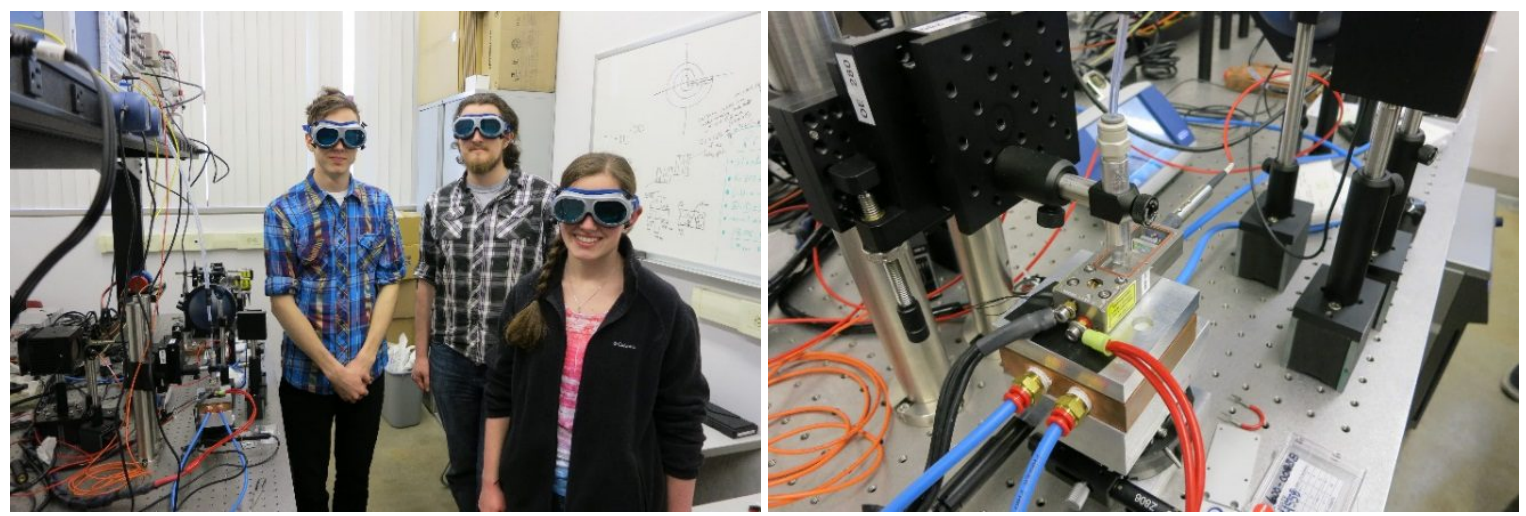

Figure 4. (a) DILAS team and (b) Autmatic volume Bragg grating alignment test system.

\section{ACKNOWLEGEMENT}

This work was supported in part by the Engineering Research Centers Program of the National Science Foundation under NSF Cooperative Agreement No. EEC-0812056 and by the Directed Energy Professional Society. The authors also wish to thank all of the companies which have sponsored projects over the years.

\section{REFERENCES}

[1] Bunch, R. M., Joenathan, C., and Siahmakoun, A., "From optics to optical engineering: 20 years of optics education at Rose-Hulman Institute of Technology" in Education and Training in Optics and Photonics, OSA Technical Digest Series, Optical Society of America, EMC4 (2003).

[2] ABET, Criteria for Accrediting Engineering Programs, Baltimore, Md.: Engineering Accreditation Commission, Oct. 26, 2013. <http://www.abet.org/eac-criteria-2014-2015/>

[3] Shoop, Barry L. and Robinson, Kathleen B., "ABET accreditation and optics and photonics engineering: an association whose time has come" Proc. SPIE 8481, 848107 (2012); doi:10.1117/12.931263

[4] Marin, J. A., Armstrong, J. E. and Kays, J. L. "Elements of an Optimal Capstone Design Experience" Journal of Engineering Education 88: 19-22. (1999) doi: 10.1002/j.2168-9830.1999.tb00405.x

[5] Joenathan, C., Bunch, R. M., and Siahmakoun, A., "Project oriented laboratory courses in optics education" in 1995 International Conference on Education in Optics, M.J. Soileau, Editor, Proc. SPIE 2525, 266-271 (1995).

[6] Joenathan, C., Bunch, R. M., and Siahmakoun, A., "Learning By Building:Optical Prototype Based Project Course" Optics \& Photonics News, Nov. $42-44$ (1999).

[7] Dutson, A. J., Todd, R. H., Magleby, S. P., and Sorenson, C. D., "A Review of Literature on Teaching Design Through Project-Oriented Capstone Courses," Journal of Engineering Education 76, 17-28 (1997).

[8] Bunch, R. M., Lepkowicz, R. S., Granieri, S. C., "Rethinking optical engineering capstone design experience" Proc. SPIE 7783, 778300 (2010).

[9] McLeod, S. A., "Likert Scale" $2008<$ http://www.simplypsychology.org/likert-scale.html> (1 August 2014).

[10] Leisher, Paul O., Kirkpatrick, Scott, Liptak, Richard W., Granieri, Sergio, Bunch, Robert M "An activity in design for manufacturability - concept generation through volume production in less than three hours" Proceedings of the 2014 ASEE Annual Conference, Indianapolis, IN, June 2014 Paper ID \#9232 